\title{
CLIMATE CHANGE IMPACTS ON URBAN STORMWATER BEST MANAGEMENT PRACTICES
}

\author{
ZUBAYED RAKIB $^{1}$, MICHAEL BARBER $^{1} \&$ ROBERT MAHLER $^{2}$ \\ ${ }^{1}$ Civil and Environmental Engineering, University of Utah, Salt Lake City, UT, USA. \\ ${ }^{2}$ Soil Science Division, University of Idaho, Moscow, ID.
}

\begin{abstract}
Total maximum daily load (TMDL) studies determine the amount of contaminant(s) that can be discharged daily from point (waste load allocation - WLA) and nonpoint (load allocation - LA) sources including a margin of safety (MOS) and then layout the path for achieving these levels by reductions in loadings. This has caused environmental agencies to require best management practices (BMPs) for control of urban stormwater contributions. Design storms for volume-based and peak discharge BMPs are typically determined from historic precipitation and runoff records that do not adequately address the impacts of climate change. We examine a 10-year period of predicted flows in the Spokane River watershed under 2050 climate predictions to determine the amount of additional LA removal required to meet water quality goals. While the current TMDL proposes a $50 \%$ reduction of nonpoint loading, our results indicate this will not be adequate. The implication is that urban BMPs are currently inadequately designed to handle nonpoint pollution in areas projected to experience increased precipitation events. The problem is particularly acute for rain on snow events where BMP performance is already impaired.

Keywords: algal blooms, hydrodynamic simulation, nonpoint source pollution, nutrients, total maximum daily loads, waste load allocation, water quality modeling.
\end{abstract}

\section{INTRODUCTION}

In the United States, under section 303(d) of the Clean Water Act, states are required to create pollution budgets and reduction plans for waters not meeting beneficial use standards [1]. These total maximum daily load (TMDL) studies determine the amount of contaminant(s) that can be discharged daily from point (waste load allocation - WLA) and nonpoint (load allocation - LA) sources including a margin of safety (MOS) and then layout the path for achieving these levels by reductions in loadings. Stormwater runoff from impervious urban and suburban development can contribute to significant degradation of streams and rivers [2]. Since many TMDL studies have been performed using steady state models such as QUAL2Kw [3-6], owning to the fact that point sources were historically identified as both the main source and the main opportunity, properly accounting for stormwater pollution has not been adequately addressed. Previous studies have shown that low flow analysis do not necessarily capture the largest inputs of nutrients [7]. The likely result is that stormwater best management practices (BMPs) may not be properly accounted for in the pollution budget. This is especially true when considering the impacts of climate change on future precipitation events.

Design storms for volume-based and peak discharge BMPs are typically determined from historic precipitation and runoff records that do not adequately address the impacts of climate change. The stakes are immensely important as overdesigning BMPs wastes money but 
undersizing BMPs is not protective of the environment and potentially leads to more expensive solutions in the future.

This study used the Spokane River Basin in northeastern Washington, USA as the basis for evaluating the hypothesis that climate change should be factored into BMP designs when planning LAs. We examine a 10-year period (1999-2009) of predicted flows in the Spokane River watershed under 2050 climate predictions to determine if additional LA removal will be required to meet water quality goals. This study modified an existing U.S. Army Corps of Engineers CE-QUAL-W2 model [8] to simulate hydrology and water quality with particular attention to flow, phosphorus, nitrogen, dissolved oxygen, and river temperature. The original model was used to develop the Spokane River dissolved oxygen TMDL based on a 2001 lowflow analysis [9]. By calibrating and applying the model for an extended period, we were able to better predict the nutrient dynamics under varying a variety of flow conditions and facilitate investigation and decisions regarding permissible nutrient levels that include a variety of hydrologic conditions. Implications to BMP design were discussed.

\section{BACKGROUND}

The Spokane River watershed is located in northeastern corner of the State of Washington, USA (Fig. 1). As a result of low summer flow conditions, sections of the river have been listed as impaired including Long Lake, which has dissolved oxygen (DO) concentrations below beneficial use standards. In order to attain the DO requirement, significant reductions in nutrient loadings much be achieved. In the U.S., this is done through WLA. WLA is the pollutant load allocated to current and future point sources (including Municipal Separate Storm Sewer System (MS4) and other permit-recognized nonpoint sources). It is part of the TMDL calculation according to:

$$
\mathrm{TMDL}=\mathrm{WLA}+\mathrm{LA}+\mathrm{RC}+\mathrm{MOS},
$$

where LA are additional nonpoint sources, RC is reserve capacity for future growth, and MOS is margin of safety. Since TMDLs are typically triggered when water quality impairment has been identified, WLAs often require some amount of reduction in current loading,

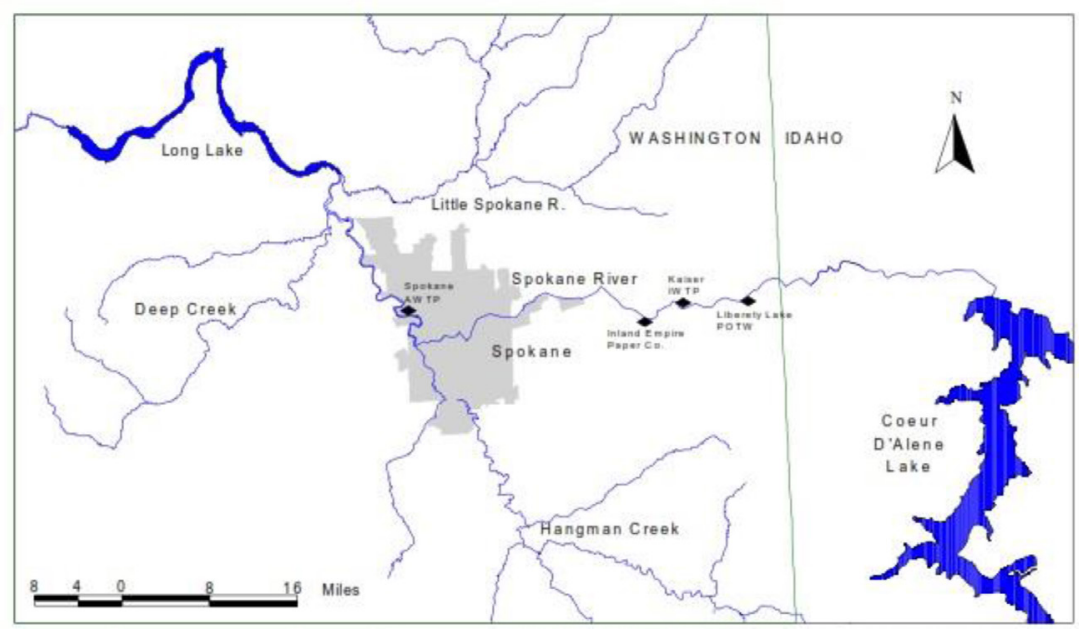

Figure 1: Spokane River Bain in Northeastern Washington State, USA [7]. 
which may involve installation of costly new or improved treatment systems or nonpoint source BMPs.

LA reduction is done primarily through implementation of stormwater BMPs such as detention ponds, constructed wetlands, grassy swales, and other control devices [10]. BMPs typically fall into one of two categories depending on whether sizing is controlled by flow rate or flow volume. The Washington State Department of Ecology and the Washington Department of Transportation recommend using a 3-hour short-duration storm distribution for flow-based BMPs and a 30-hour long-duration storm hyetograph for volume-based BMPs in the Spokane, Washington area [11]. These storms durations are the result of a large collaborative effort between various stormwater entities in eastern Washington. The return interval (e.g. 0.5, 2, 5, 10, 25, 50, 100, PMF) varies depending on the nature of the structure and the goal (quality vs quantity) of the BMP. The concerning feature of this is that Washington's isopluvial maps are based on NOAA Atlas 2, Volume 9 published in 1973 [12]. Thus, BMPs are being designed ignoring more than 40 years of climate induced precipitation changes.

Accurately downscaling precipitation forecasts for future climate scenarios is an extremely challenging pursuit given the high temporal and spatial variability of rainfall $[13,14]$. As a result, we did not attempt to redefine the isopluvial maps and conduct a microscale analysis of individual BMPs for this project. Instead, we examined large-scale nonpoint source loading under present and future scenarios and inferred this to BMP design requirements.

\section{METHODOLOGY}

This study modified the CE-QUAL-W2 model [12] to simulate hydrology and water quality over a 10-year historic period (1999-2009), with particular attention to flow, phosphorus, nitrogen, dissolved oxygen, and river temperature. The model consisted of 188 longitudinal segments and an average of nearly 20 layers in vertical direction. The flow portion of the model was calibrated/validated using existing USGS gaging stations and known reservoir levels. In addition to the main flow entering from Post Falls Dam, tributary inflows from Hangman Creek, Little Spokane River, Coulee Creek, and wastewater discharges from the area were added. As the majority of dams on the river represented so-called 'run of the river facilities', few adjustments had to be made for changing reservoir storage levels. Groundwater interactions, although significant sources/sinks of water, were assumed to be constant through each simulation year.

Once the model successfully reproduced the flows of the 10-year period, water quality portion of the model was calibrated and validated using available data. Concentration data from State monitoring activities and reported Waste Water Treatment Plant discharges were used to examine the predictive capabilities of the model.

The impacts of climate and population change were then added to the model. The 2050 model runoff scenarios were developed using flow projections developed by the Climate Impacts Group at the University of Washington. Efforts were made to use the latest data available for this study. So, while meteorological data were available from CMIP5 models for RCP4.5 and RCP8.5 scenarios, flow projections were not yet completed. Therefore, CMIP3 flow data for B1 scenario were used in combination with CMIP5 meteorological data for the RCP4.5 scenario, while CMIP3 flow data for A1B scenario were used with CMIP5 meteorological data for the RCP8.5 scenario. Such a combination provided a better job of bracketing the range of plausible future greenhouse gas forcing in the Pacific Northwest.

Stream temperatures at the boundary conditions (WA-ID Stateline, Hangman Creek, Little Spokane River, and Coulee Creek) for the projected time scale (2041-2050) were estimated 
from available air temperature projections. Previous studies have demonstrated this relationship is well described by a continuous S-shaped function [15]. Spokane River and its tributaries (Hangman Creek and Little Spokane River) generally do not experience freezing temperatures. To take this into account, a parameter $\mu$ was added to represent the estimated minimum stream temperature to produce:

$$
T_{s}=\mu+\mu+\frac{\alpha-\mu}{1+e^{\gamma\left(\beta-T_{a}\right)}},
$$

where $T_{s}$ is the estimated stream temperature, $T_{a}$ is the measured air temperature, $\alpha$ is the estimated maximum stream temperature, $\gamma$ is a function of the slope at the point of inflection, and $\beta$ represents the air temperature at the inflection point.

Changes were also made to account for population growth. According to the State Office of Financial Management forecasts, the population in Spokane County will increase from 441,600 persons in 2005 to more than 593,000 by 2040. Discharge data at Spokane WWTP was collected from the City of Spokane to understand the change in flow rate with changing population and operation practice. When compared, it was seen that there was a clear increase in average flows from Spokane WWTP $\left(1.4 \mathrm{~m}^{3} / \mathrm{sec}\right.$ in $1980 \mathrm{~s}, 1.7 \mathrm{~m}^{3} / \mathrm{sec}$ in $1990 \mathrm{~s}$, $2.0 \mathrm{~m}^{3} / \mathrm{sec}$ in $2000 \mathrm{~s}$; an increase of approximately $20 \%$ per decade). It was important to look at the projected population that will be served by the WWTP, and not just the overall population increase in the area. Subsequently, the population trend and discharge trends were used to come up with the estimates for WWTP discharges for 2041-2050 - which was 6.8$7.0 \mathrm{~m}^{3} / \mathrm{sec}$. The discharge estimated for 2025 using the same trends was $2.6 \mathrm{~m}^{3} / \mathrm{sec}$, which was close to the estimate of $2.8 \mathrm{~m}^{3} / \mathrm{sec}$ given by the Spokane County. This provided a check for the 2041-2050 estimates used in this study.

\section{RESULTS AND DISCUSSION}

Although most climate models predict a modest increase in precipitation over the entire Pacific Northwest, model projections for the Spokane watershed show fairly large percentage increase particularly during the winter months. In examining these results we concluded that rain (due to temperature increases) in winter months rather than snow disproportionately skewed percentage increases during the December to March time frame (see Table 1). Historically these were relatively low flow months with snow generating large May and June runoff events. Over a 10-year simulation period, Fig. 2 illustrates the serious magnitude of the flow increases.

Water temperature at surface in the Spokane River and Long Lake, as seen from climate change scenario simulations, is expected to increase during 2040-2050 due to the projected increase in air temperature. Figure 3 illustrates the projected stream temperatures at the Spokane River at Spokane gage. Compared to the baseline scenario, water temperature at river locations is expected to increase by about $0.6^{\circ} \mathrm{C}-0.8^{\circ} \mathrm{C}$ for the high and low emission scenarios during 2040-2050; while at Long Lake, the increase is about $1.8^{\circ} \mathrm{C}-2.2^{\circ} \mathrm{C}$.

Figure 4 compares the projected average monthly water temperatures at the Spokane River at Spokane gaging location. As illustrated, results indicate temperatures generally increased in all months. These increases led to additional violations of the stream temperature standards. Violation of the temperature criteria under climate change impacts was also apparent from vertical plots at a number of other reaches along the study corridor. As expected, the vertical profiles indicated that surface temperatures were warmer than average temperature exacerbating the problem. 
Table 1: Projected \% increases in streamflow by month.

\begin{tabular}{llccc}
\hline \multirow{2}{*}{ Month } & \multicolumn{2}{c}{ Spokane River @ Spokane } & \multicolumn{2}{c}{ Long Lake Reservoir } \\
\cline { 2 - 5 } & $\begin{array}{c}\text { High emission } \\
\text { scenario }\end{array}$ & $\begin{array}{c}\text { Low emission } \\
\text { scenario }\end{array}$ & $\begin{array}{c}\text { High emission } \\
\text { scenario }\end{array}$ & $\begin{array}{c}\text { Low emission } \\
\text { scenario }\end{array}$ \\
\hline January & 132.4 & 88.2 & 127.8 & 90.4 \\
February & 235.3 & 147.1 & 214.9 & 138.7 \\
March & 123.1 & 88.9 & 103.7 & 77.5 \\
April & 69.7 & 57.9 & 16.2 & 25.4 \\
May & 13.8 & 27.8 & 8.1 & 14.2 \\
June & 4.5 & 9.8 & 18.3 & 14.7 \\
July & 15.3 & 11.8 & 9.7 & 6.3 \\
August & 24.0 & 28.0 & 14.2 & 5.7 \\
September & 17.6 & 5.9 & 29.7 & 19.8 \\
October & 25.0 & 16.7 & 88.7 & 61.3 \\
November & 35.3 & 17.6 & 129.6 & 83.4 \\
December & 127.3 & 86.4 & 196.5 & 133.8 \\
\hline
\end{tabular}

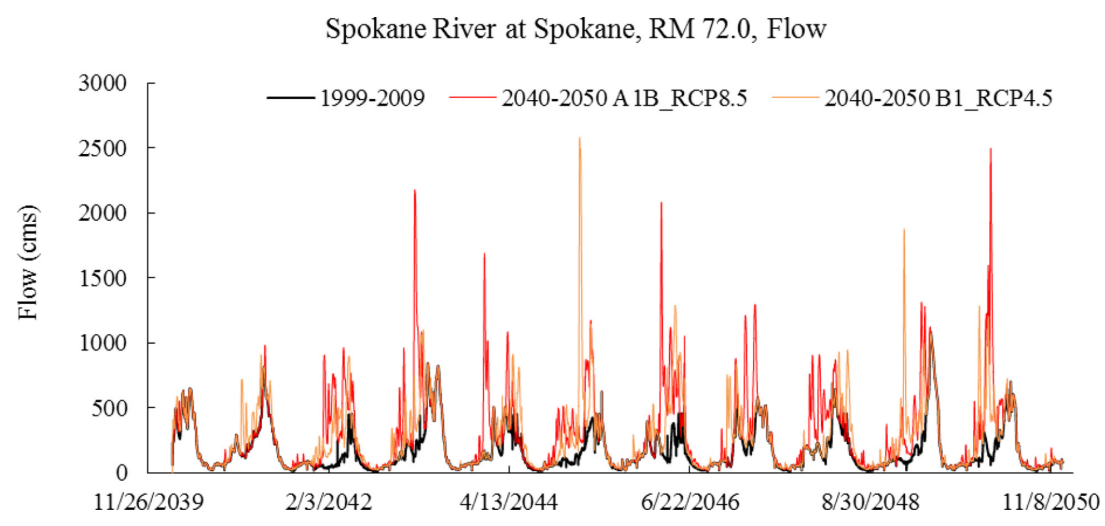

Figure 2: Future flow projections.

Similarly, Fig. 5 illustrates the changes in average monthly dissolved oxygen concentrations at the same location as Fig. 4. While winter months indicate slightly improved DO concentrations as a result of future climate change, the critical summer period concentrations are nearly the same (in July) or slightly worse (in August). The daily fluctuations (shown in Fig. 6) more clearly demonstrate the variability and potential problems associated with 


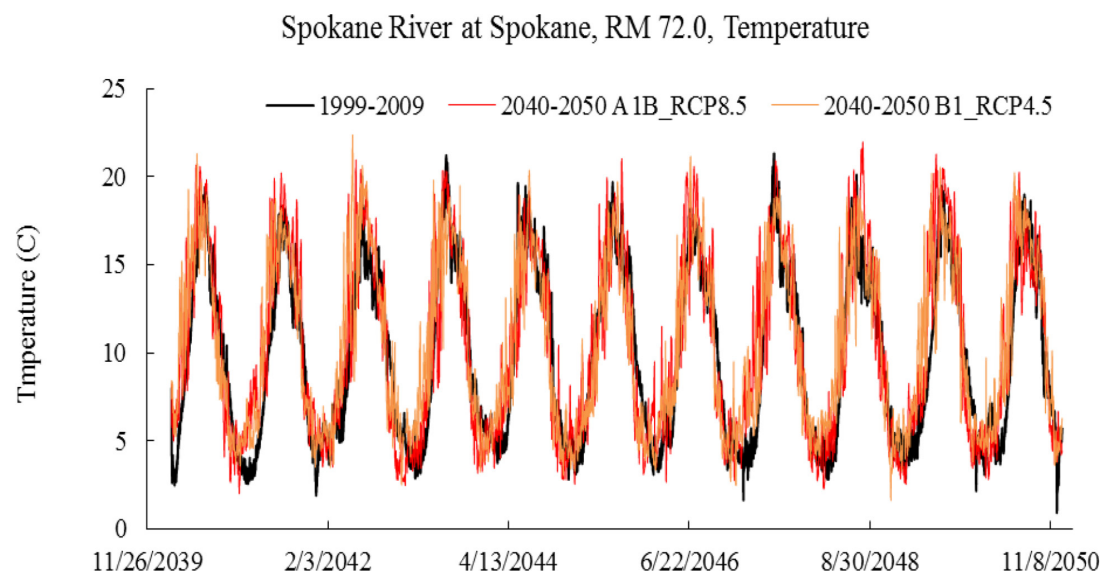

Figure 3: Climate change model simulation results for stream temperature.

Spokane River at Spokane, RM 72.0, Temperature

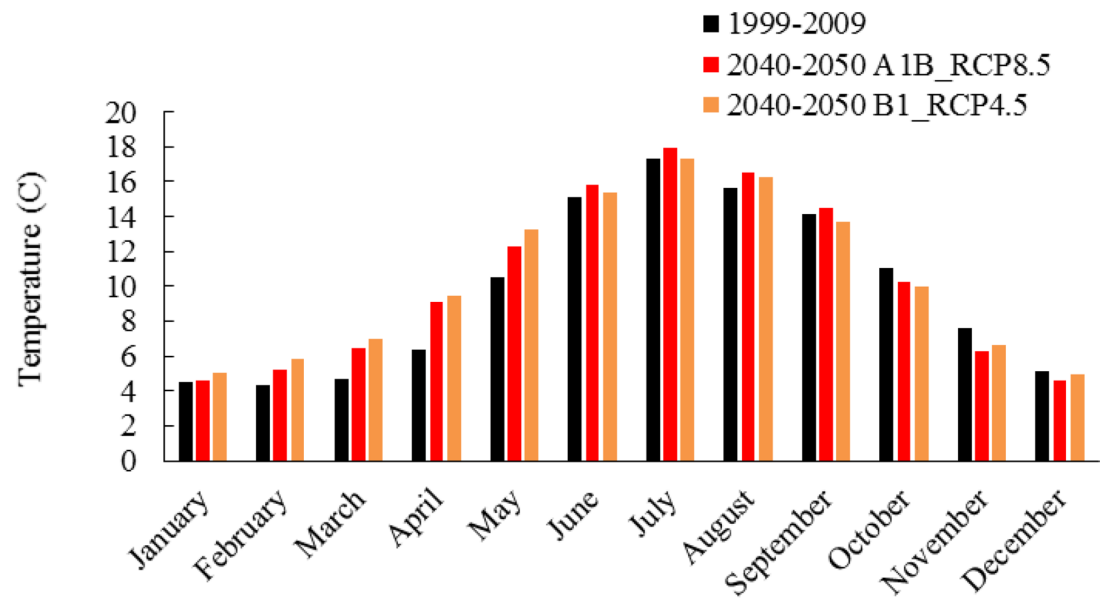

Figure 4: Climate scenario temperatures at monthly time scale.

low dissolved oxygen concentrations as several additional low concentration periods are predicted. For the winter period, snowmelt impacts overcome the slight increase in air temperature and DO is improved. However, during the summer, the increases in stream flow are offset by the impacts of warmer air temperatures.

In fact, average concentrations during late summer are very close to the DO standard. Statistical analysis showed the dissolved oxygen concentration differences between the baseline and climate scenarios at different river locations were statistically significant (0.05 significance level, $\mathrm{p}<0.005)$ but were not for concentrations in Long Lake $(\mathrm{p}>0.1)$. This implies the issue with low DO at Long Lake during the summer will persist in the future. Oxygen at depth seemed to suffer as well (see Fig. 7) presumably due to increased temperature reducing oxygen flux from the atmosphere and higher algal activity shown in Fig. 8. 


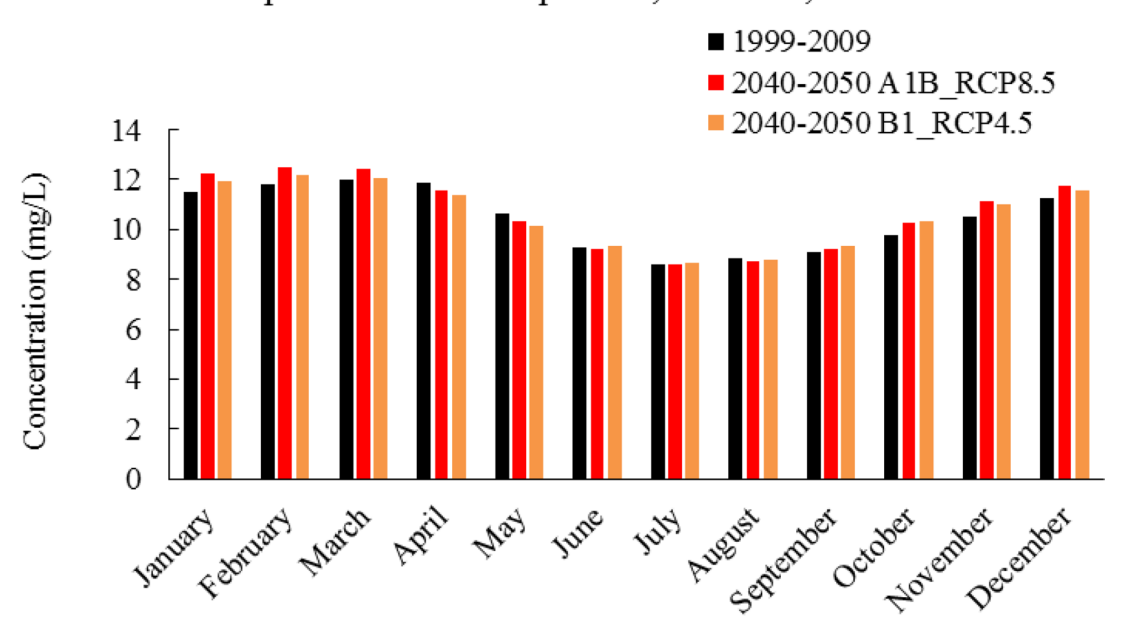

Figure 5: Climate scenario dissolved oxygen concentrations at monthly time scale.

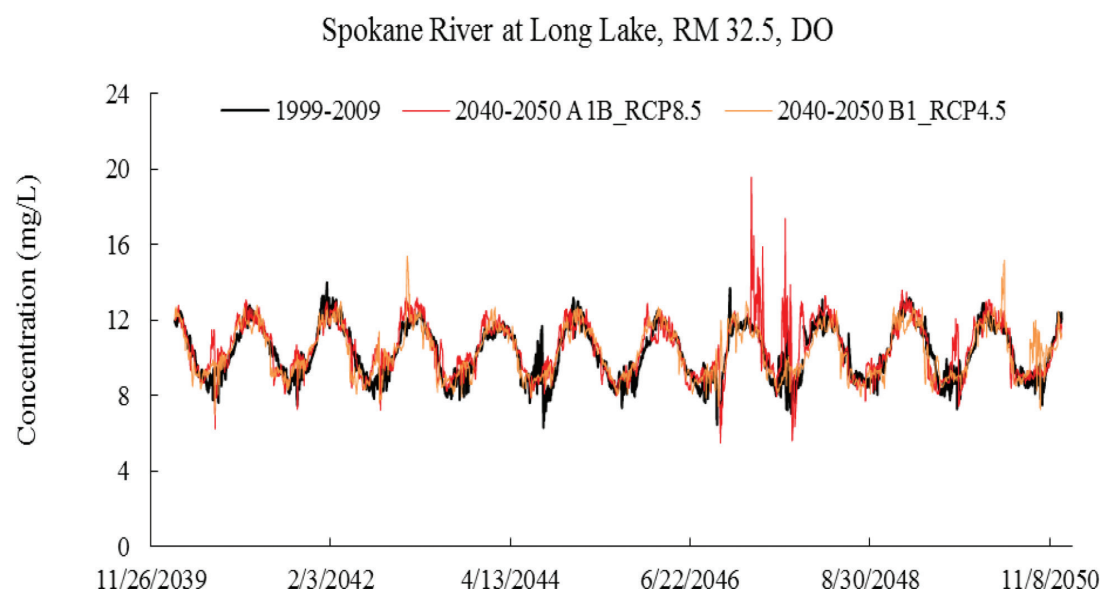

Figure 6: Daily dissolved oxygen concentrations at Long Lake.

The TMDL developed for the Spokane River calls for a 50\% reduction in nutrient loading from nonpoint sources. Simulation results from this investigation indicate that this will not be sufficient to protect aquatic species dependent on dissolved oxygen for survival. The number and size of stormwater BMPs in the watershed need to be increased to account for the additional flow. While not all regions of the Pacific Northwest are expected to see increases in climate-induced precipitation, it seems important to plan and design future BMPs with additional capacity to meet water quality objectives.

\section{CONCLUSIONS AND RECOMMENDATION}

Design of stormwater BMPs taking climate change into consideration remains a challenging task. While our approach was different than other studies $[14,16]$, the wide variability was similar. A 2011 study by Forsee and Ahmad found that 6-hour, 100-year precipitation depth varied from a reduction of $30 \%$ to an increase of $300 \%$ depending on the model 

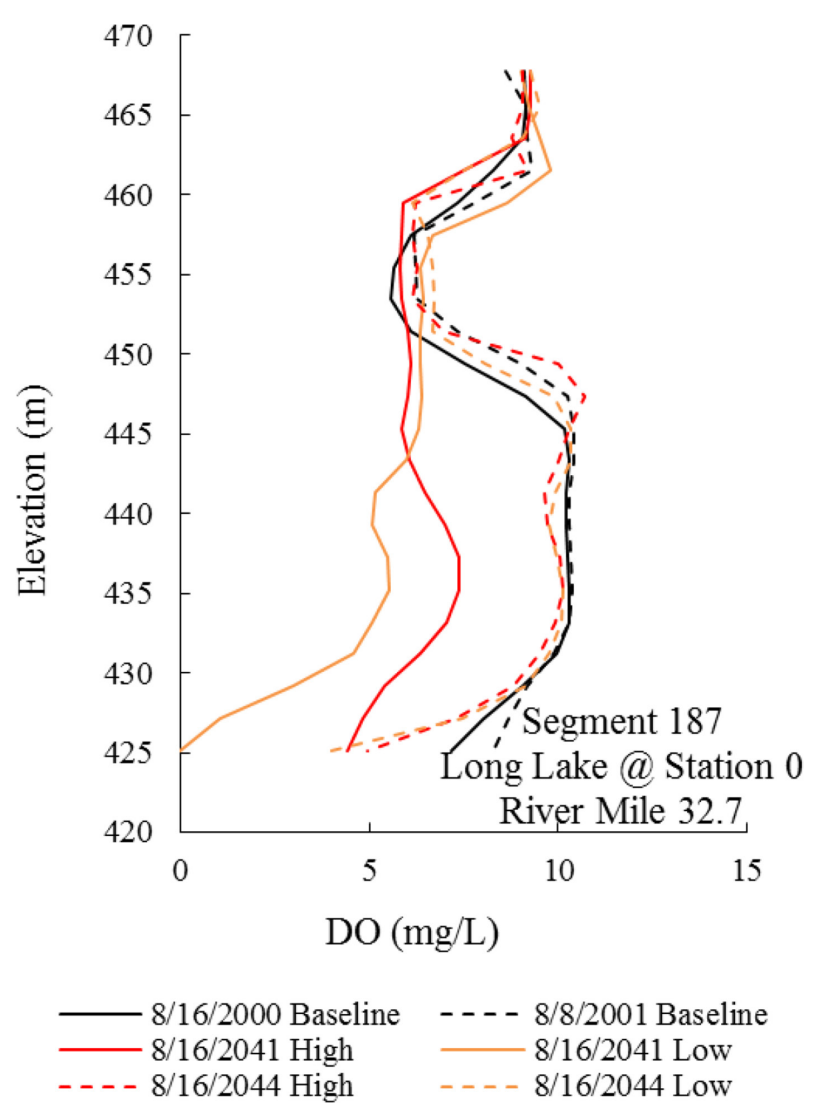

Figure 7: Vertical profile of dissolved oxygen in Long Lake.

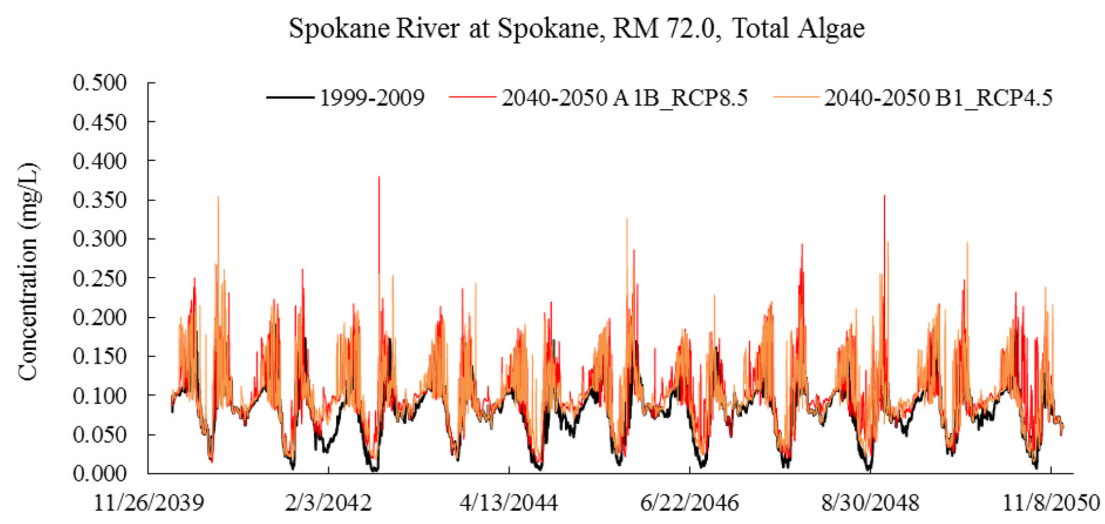

Figure 8: Climate impacts on total algae concentrations.

used. In our study, runoff amounts increased from $4.5 \%$ to $235 \%$. While in some cases this resulted in lower concentrations, total loads (concentration $\times$ flow) were still high and the associated increase in algae production detrimentally impacted dissolved oxygen concentrations during die-off. However, despite the variability, it is readily apparent that BMPs 
must be sized to treat additional volumes and increased peak discharges of flow. The precise magnitudes of these increases still needs further study as the consequences are significant. At the high end, BMPs would need to be more than double their size to treat $235 \%$ more runoff.

One additional challenge that needs to be addressed is the wintertime shift in large rainon-snow runoff events. Many existing BMPs do not function well (or at all) during dormant vegetation periods. Infiltration, stormwater inlets, and wetland vegetation all have significant challenges during winter months. The cycling of nutrients in lakes, however, means that stormwater controls must be effective for all stormwater design events.

More research is still needed to reduce the uncertainty of downscaled precipitation forecasts and frequency analysis. However, this study indicates that additional stormwater control is not adequately accounted for in historic analysis of flow conditions.

\section{ACKNOWLEDGEMENTS}

This project was funded by the United State Department of Agriculture National Institute of Food and Agriculture through their AFRI Climate Change program.

\section{REFERENCES}

[1] U.S. Environmental Protection Agency, Handbook for developing watershed TMDLs. Office of Wetlands, Oceans, and Watersheds, Washington, DC, 2008.

[2] U.S. Environmental Protection Agency. National management measures to control nonpoint source pollution from urban areas. EPA-8410B-05-004, Office of Water, Washington, DC, 2005.

[3] Pelletier, G.J., Chapra, S.C. \& Hua, T., QUAL2Kw e A framework for modeling water quality in streams and rivers using a genetic algorithm for calibration. Environmental Modelling and Software, 21, pp. 419-425, 2006. http://dx.doi.org/10.1016/j.envsoft.2005.07.002

[4] Turner, D., Pelletier, G. \& Kasper, B., Dissolved oxygen and pH modeling of a periphyton dominated, nutrient enriched river. ASCE Journal of Environmental Engineering, 135(8), pp. 645-652, 2009. http://dx.doi.org/10.1061/(ASCE)0733-9372(2009)135:8(645)

[5] Neilson, B.T., Hobson, A.J., Vonstackelberg, N., Shupryt, M. \& Ostenmiller, J., Using Qual2K modeling to support nutrient criteria development and wasteload analyses in Utah. Final Project Report. Utah Department of Environmental Quality. Division of Water Quality. Salt Lake City, UT, 2012.

[6] von Stackelberg, N. \& Neilson, B., Collaborative approaches to calibration of a riverine water quality model. Journal of Water Resources Planning and Management, 140(3), pp. 393-405, 2014. http://dx.doi.org/10.1061/(ASCE)WR.1943-5452.0000332

[7] Rakib, Z., Barber, M. \& Mahler, R., Modeling flow, nutrient and dissolved oxygen concentrations in the Spokane River under multiple year conditions. 8th International conference on Sustainable Water Resources Management, A Coruna, Spain, June 2015.

[8] Cole, T.M. \& Wells, S.A., CE-QUAL-W2: a two-dimensional, laterally averaged, hydrodynamic and water quality model, version 3.6. Department of Civil and Environmental Engineering, Portland State University, Portland, OR, available at: http://www.cee.pdx. edu/w2/ 
[9] Clark, D.L., Kasch, M. \& Brattebo, B., Spokane River watershed strategies for point and nonpoint source management to meet the most restrictive TMDL in the nation. Proceeding of the Water Environment Federation, pp. 632-640, 2011. http://dx.doi.org/10.2175/193864711802864930

[10] International Stormwater BMP Database, available at: http://www.bmpdatabase.org/

[11] WSDOT Highway Runoff Manual M31-16.04, Washington State Department of Transportation, Olympia, Washington, April 2014.

[12] NOAA National Weather Service, Hydrometeorological Design Studies Center, available at: http://www.nws.noaa.gov/oh/hdsc/currentpf.htm.

[13] Wong, G., Maraun, D., Vrac, M., Widmann, M., Eden, J. \& Kent, T., Stochastic model output statistics for bias correcting and downscaling precipitation including extremes. American Meteorological Society, 27, pp. 6940-6959, 2014. http://dx.doi.org/10.1175/jcli-d-13-00604.1

[14] Forsee, W.J. \& Ahmad, S., Evaluating urban stormwater infrastructure design in response to projected climate change. Journal of Hydrologic Engineering, 16(11), pp. 865-873, 2011.

http://dx.doi.org/10.1061/(ASCE)HE.1943-5584.0000383

[15] Mohseni, O., Stefan, H.G. \& Erickson, T.R., A nonlinear regression model for weekly stream temperatures. Water Resources Research, 34(10), pp. 2685-2692, 1998. http://dx.doi.org/10.1029/98WR01877

[16] Mailhot, A., Duchesne, S., Caya, D. \& Talbot, G., Assessment of future change in intensity-duration-frequency (IDF) curves for Southern Quebec using the Canadian Regional Climate Model (CRCM). Journal of Hydrology, 347(1-2), pp. 197-210, 2007. http://dx.doi.org/10.1016/j.jhydrol.2007.09.019 